Ensino

\title{
O uso de tecnologias digitais no ensino de cálculo na UFPel: Uma análise acerca das iniciativas do projeto GAMA
}

\author{
The use of digital technologies in calculus teaching at UFPel: An analysis \\ of GAMA project initiatives
}

\section{Cícero Nachtigall'(i), Henrique David Campelo'(i), Pierre Teixeira da Silva ${ }^{1}\left({ }^{\circ}\right.$, Rejane Pergher $^{\prime}(\mathbb{D})$}

'Universidade Federal de Pelotas, Pelotas, RS, Brasil

\section{RESUMO}

Este trabalho procurou abordar o uso de tecnologias que visam potencializar a aprendizagem em matemática no âmbito universitário. Buscou-se identificar impactos das iniciativas do projeto GAMA: Grupo de Apoio em Matemática da Universidade Federal de Pelotas - UFPel que utilizam Tecnologias Digitais de Informação e Comunicação - TDIC para criar e disponibilizar recursos audiovisuais de apoio e espaços virtuais colaborativos. A primeira parte deste estudo relata a experiência do projeto na produção de vídeos pedagógicos. Dentre outros aspectos, fez-se uma apresentação do processo de elaboração e disponibilização dos vídeos no referido canal, bem como a sua utilização nas atividades do GAMA. A segunda parte do trabalho relatou a experiência do projeto com os grupos no WhatsApp, que foram criados com o objetivo de oferecer espaços virtuais colaborativos. Em particular, apresenta-se o resultado de uma investigação que analisou o conteúdo de 3.647 mensagens postadas por estudantes, bolsistas e professores nos dois grupos existentes. Os resultados da pesquisa permitem concluir que os recursos, recentemente agregados às atividades do GAMA, representaram alternativas importantes para potencializar o processo de ensino/aprendizagem em matemática, redimensionando e ressignificando o espaço tradicionalmente atribuído à sala de aula.

Palavras-chave: Ensino e aprendizagem de cálculo; Tecnologias digitais de informação e comunicação;. Ambientes colaborativos

\section{ABSTRACT}

This paper sought to address the use of technologies aimed at enhancing mathematical learning at the university level. We sought to identify impacts of the GAMA project initiatives: Mathematics Support Group of the Federal University of Pelotas - UFPel that use Digital Information and Communication Technologies (TDIC) to create and make available audiovisual support resources and collaborative virtual spaces. The first part of this study reports the project experience in the production of pedagogical videos. Among other aspects, a presentation was made of the process of elaboration and availability of the videos in the referred 
channel, as well as their use in GAMA activities. The second part of the work reported on the project experience with the WhatsApp groups, which were created with the goal of providing collaborative virtual spaces. In particular, we present the result of an investigation that analyzed the content of 3,647 messages posted by students, scholars and teachers in the two existing groups. The research results allow us to conclude that the resources recently added to GAMA activities represented important alternatives to enhance the teaching / learning process in mathematics, resizing and resignifying the space traditionally assigned to the classroom.

Keywords: Teaching and learning calculus; Digital information and communication technologies; Collaborative Environments

\section{INTRODUÇÃO}

No âmbito da educação superior, algumas questões têm despertado especial interesse das instituições de ensino, dentre elas: as dificuldades de aprendizagem em matemática, especialmente em componentes curriculares de Cálculo Diferencial e Integral. Dentre os aspectos mais preocupantes, neste contexto, destacam-se os impactos negativos que tais dificuldades acarretam, sob a perspectiva da reprovação, retenção e evasão acadêmica.

Na Universidade Federal de Pelotas - UFPel, por exemplo, mais de um terço dos cursos de graduação possuem, nos primeiros semestres de suas respectivas matrizes curriculares, componentes curriculares de Cálculo Diferencial e Integral. Estas componentes curriculares geralmente apresentam duas características peculiares, que às diferenciam das demais componentes curriculares.

A primeira destas características está associada à grande quantidade de conhecimentos matemáticos, dos níveis fundamental e médio, que o estudante precisa "movimentar simultaneamente" para compreender os conceitos de limites, derivadas e integrais. Dificilmente haverá assimilação dos conceitos específicos abordados nesta componente curricular se não houver razoável domínio e habilidade em diversos conceitos de matemática elementar.

De acordo com Dörr, Muniz e Pina Neves (2016), a articulação lógica e a familiaridade com a linguagem simbólica matemática representam pré-requisitos importantes para o estudante ingressante no ensino superior. 
A aprendizagem da Matemática no ensino superior requer a mobilização de conhecimentos algébricos e geométricos estudados na educação básica, bem como a capacidade de articulação lógica desses conhecimentos na resolução de problemas. Docentes desse nível de ensino, de modo geral, esperam que os estudantes ingressantes tenham adquirido tal fundamentação conceitual matemática na educação básica e que estejam familiarizados com a linguagem matemática mais simbólica. (DÖRR, MUNIZ, PINA NEVES, 2016, p. 1)

Na mesma direção, Gomes (2012) destaca que esta característica, quando associada à imaturidade dos estudantes ingressantes, pode representar um obstáculo que resulta, em muitos casos, na evasão acadêmica.

Uma das disciplinas que fazem parte da grade curricular de todos os cursos de Engenharia é o Cálculo Diferencial e Integral. Ministrada no início do curso, passa a ser o primeiro contato, para o aluno, com uma Matemática "diferente" daquela que trabalhava no Ensino Médio. Somada às novidades do ser universitário, muitas vezes, a imaturidade e as algumas deficiências trazidas do processo educacional anterior, a reprovação e evasão no primeiro período dos cursos de Engenharia não é novidade. (GOMES, 2012, p. 1)

A segunda característica refere-se ao caráter introdutório que as componentes curriculares de cálculo geralmente desempenham para diversos cursos de graduação em várias áreas, especialmente nas áreas de exatas e engenharias. Frequentemente essas componentes curriculares configuram, nas matrizes curriculares obrigatórias destes cursos, como pré-requisito para diversas outras componentes curriculares.

A disciplina Cálculo Diferencial e Integral, presente hoje em vários cursos de nível superior, tem como principal objetivo servir de base para as diversas carreiras, entre outras coisas, devido a sua grande aplicabilidade, desempenhando importante papel como linguagem na representação dos fenômenos e como instrumento para a resolução de problemas. (CATAPANI, 2001, p.48)

Neste contexto, as componentes curriculares de Cálculo Diferencial e Integral se apresentam, em uma perspectiva metafórica, como uma porta - por vezes bastante estreita - que liga dois mundos bastante distintos. O primeiro formado pelos conhecimentos matemáticos elementares, geralmente abordados nos níveis básicos da educação formal (ensino fundamental e médio) e, o segundo, formado pelos conceitos abordados em componentes curriculares das áreas profissionalizantes de diversos cursos 
de graduação. Assim, por um lado, estas componentes curriculares exigem que o estudante possua considerável habilidade com a matemática abordada em etapas de ensino anteriores e, por outro, ela própria é considerada um pré-requisito indispensável para inserção na realidade profissional de diversas áreas do conhecimento, permitindo modelar situações práticas e resolver diversos problemas da sociedade moderna.

Não raramente, a dificuldade na compreensão dos novos conceitos, somada a um aprendizado deficitário de conteúdos de matemática elementar representam grandes obstáculos e tornam a aprendizagem praticamente inacessível a muitos estudantes. Segundo Reis (2001, p. 201), a disciplina de cálculo "desempenha, simultaneamente, o papel de ponte e de síntese entre um pensamento matemático mais elementar (relacionado a conteúdos como números e funções) e um pensamento mais avançado (relacionado a conteúdos como derivadas e integrais)".

Com o objetivo de potencializar o aprendizado em matemática na UFPel, um grupo de professores do Instituto de Física e Matemática (IFM/UFPel), com apoio da Pró - Reitoria de Graduação (PRG/UFPel), atual Pró - Reitoria de Ensino (PRE), criou em 2010 o Projeto Tópicos de Matemática Elementar: Matemática Básica - Iniciação ao Cálculo, que passaria a se chamar Projeto GAMA: Grupo de Apoio em Matemática a partir de 2015. Desde então, participam do GAMA, em média 500 estudantes vinculados a mais de 30 cursos de graduação da UFPel.

Tendo em vista o perfil heterogêneo dos estudantes, busca-se oferecer diversas atividades ao longo dos semestres letivos e nos recessos acadêmicos. As principais atividades são cursos de revisão em matemática elementar (níveis fundamental e médio) nas férias, geralmente nas semanas anteriores ao começo do semestre letivo, além de aulas de revisão aos sábados, ao longo de todo o semestre letivo, abordando conceitos de matemática elementar e conteúdos tipicamente estudados em nível de graduação, tais como os de Cálculo Diferencial e Integral, Geometria Analítica e Álgebra Linear. Além das aulas de reforço, o projeto GAMA oferece monitorias ao longo de todo o semestre letivo, em vários dias, locais e horários. 
Desde a sua criação, o GAMA procura oferecer espaços e atividades que propiciem melhores condições para a aprendizagem em matemática. Nesta perspectiva, as Tecnologias Digitais da Informação e Comunicação (TDICS) representam uma alternativa potencialmente eficiente no processo de ensino/aprendizagem, na medida em que incentivam a autonomia do discente, proporcionam, simultaneamente, espaços virtuais destinados à interação e colaboração entre pares, atribuindo assim, ao professor, um papel de orientador e oferecendo ao estudante a possibilidade de assumir o papel de protagonista no processo educativo.

Durante o ano de 2017, um grupo formado por dois professores colaboradores e um bolsista do projeto GAMA, dois dos quais são os primeiros autores deste trabalho, iniciaram as primeiras tentativas para viabilizar a gravação e disponibilização das aulas oferecidas pelo GAMA no formato de vídeos pedagógicos, no YouTube.

Com esta iniciativa, buscou-se propiciar uma alternativa de aprendizagem aos estudantes da UFPel, tanto para aqueles que já participavam das atividades do GAMA mas que, por algum motivo, não se sentiam à vontade para pedir a retomada da explicação durante a atividade presencial, quanto para aqueles que não possuem disponibilidade para assistirem as aulas de reforço.

Paralelamente à iniciativa dos vídeos pedagógicos surgiu, em novembro de 2018, uma questão interessante trazida por um dos bolsistas do GAMA, o terceiro autor desta pesquisa, à coordenação do projeto uma vez que este relatou que durante o seu horário de monitoria não havia atendido nenhum aluno (presencialmente), entretanto neste mesmo horário ele ajudou uma aluna através do aplicativo WhatsApp. A partir daí observou-se a possibilidade de criação de um grupo no referido aplicativo como recurso para o atendimento à distância, contemplando assim estudantes interessados em discutir questões relacionadas aos conteúdos de Cálculo, mas que por algum motivo não conseguiram se fazer presentes nos dias, horários e locais das atividades presenciais do GAMA, ou então simplesmente porque a dúvida surgiu durante a resolução da lista, em horários em que não haviam monitorias do GAMA, como por exemplo nos horários noturnos compreendidos entre $22 \mathrm{~h}$ e $6 \mathrm{~h}$ ou mesmo aos sábados, domingos e feriados. 
No dia 17 de novembro de 2018 foi criado, neste contexto, um grupo no WhatsApp com o objetivo de proporcionar um espaço colaborativo e de integração entre estudantes de diversos cursos da UFPel, esclarecer dúvidas dos alunos, divulgar as aulas, comunicar alterações nos locais e horários de monitoria durante o semestre, dentre outros assuntos relacionados ao estudo. O grupo foi criado e administrado, inicialmente, pelos autores deste trabalho, o qual contava com a presença de estudantes que participavam das atividades do GAMA naquele semestre, de diversos cursos da UFPel, além de bolsistas e professores.

Neste contexto, este trabalho apresenta um estudo acerca dos impactos e contribuições destas duas iniciativas, que propõem a incorporação das TDICs como recursos que visam agregar qualidade às atividades de apoio historicamente oferecidas pelo projeto GAMA. Cabe salientar que, tanto a utilização do aplicativo WhatsApp quanto o acesso aos vídeos do projeto GAMA na plataforma YouTube são gratuitos. Destaca-se a seguir a pergunta norteadora desta pesquisa: Quais impactos, sob a perspectiva da atuação pedagógica do projeto GAMA, podem ser percebidos após a implementação destas duas iniciativas?

\section{REFERENCIAL TEÓRICO}

No contexto educativo contemporâneo, as TDICs apresentam-se como potenciais aliadas no processo de ensino/aprendizagem. Os avanços e as consequentes facilidades proporcionadas às novas gerações, especialmente pelo advento da internet e dos smartphones, criaram formas de estabelecer relações sociais e impactaram, inevitavelmente, no processo educativo. Particularmente, várias atividades que, há alguns anos, eram indispensáveis (como reuniões e aulas com dias, horários e locais préestabelecidos) passam a ser questionados e, não raramente, evitados, optando-se pela comunicação à distância e uso de recursos online. Os estudantes contemporâneos e seus professores estabelecem, assim, novos olhares e novas relações com os outros, consigo mesmos e com a sua aprendizagem. Como salienta Moran (2013), as tecnologias digitais 
possibilitam novas perspectivas para o processo de ensino/aprendizagem, oferecendo novos meios que ressignificam o conceito de sala de aula e o tempo da aprendizagem.

As tecnologias digitais móveis desafiam as instituições a sair do ensino tradicional, em que o professor é o centro, para uma aprendizagem mais participativa e integrada, com momentos presenciais e outros com atividades a distância, mantendo vínculos pessoais e afetivos, estando juntos virtualmente. Podemos utilizar uma parte do tempo de aprendizagem com outras formas de aulas, mais de orientação a distância. Não precisamos resolver tudo dentro da sala de aula. (MORAN, 2013, p. 30)

Os vídeos e, particularmente, os vídeos pedagógicos, se disseminaram na sociedade moderna de tal forma que sua utilização no contexto educacional vem sendo cada vez mais comum, tanto de forma orientada quanto autônoma. Como destaca Borba e Oechsler (2018), a democratização no acesso a estes recursos tem despertado especial interesse da sociedade.

Com o advento da internet rápida e a facilidade com que se tem acesso a equipamentos que permitem a gravação de áudio e imagens em melhor resolução e com preços cada vez mais acessíveis à população, os vídeos tornaram-se uma espécie de fascínio para muitos. (BORBA e OECHSLER, 2018, p. 392)

Nesta mesma direção, Gallo e Pinto (2010, p. 4) destacam que o mundo real e o virtual se complementam e estabelecem diferentes formas de interação do aprendiz com o objeto de aprendizagem, que "por meio de uma combinação de mídias digitais como imagem, áudio, vídeo, texto e animação, também permite a interação do aluno com o objeto de conhecimento".

Como destacam Neto, Versuti e Vaz (2016) existe uma falta de sintonia tecnológica/didática entre docentes e alunos. Segundo os autores, o ensino tem sofrido com a falta de interesse por parte dos estudantes, pois principalmente para os jovens, a interatividade tornou-se fundamental. Esta falta de sintonia prejudica o processo educativo.

Acredita-se então que o celular, dentro desta perspectiva de aprendizagem móvel, pode ser utilizado como meio para suscitar nos alunos maior interesse pela disciplina. Os aplicativos sociais, como o WhatsApp, fornecem a facilidade e o grau de interatividade necessária como método para 
estimular o aluno a aprender, motivando novas formas de relacionamento no processo ensino e aprendizagem. Para isso é preciso avaliar o uso de aplicativos de redes sociais virtuais por meio do smartphone, para fins educacionais, e sua função como ferramenta facilitadora para o ensino, como estratégia alternativa às abordagens tradicionais. (NETO, VERSUTI e VAZ, 2016, p. 3)

\section{METODOLOGIA}

Nesta seção, são apresentados os percursos metodológicos desta pesquisa. Primeiramente, são abordados aspectos relacionados aos vídeos pedagógicos produzidos e disponibilizados pelo GAMA no canal do projeto no YouTube bem como a utilização destes nas atividades desenvolvidas. A segunda parte desta seção apresenta a metodologia utilizada para coleta e análise das mensagens postadas por estudantes, bolsistas e professores em dois grupos no aplicativo de mensagens WhatsApp. A análise dos dados obtidos nas respostas dos questionários foi realizada utilizando a técnica de análise de conteúdo (AC). Bardin (2016) define a análise de conteúdo como

Um conjunto de técnicas de análise das comunicações visando obter por procedimentos sistemáticos e objetivos de descrição do conteúdo das mensagens indicadores (quantitativos ou não) que permitam a inferência de conhecimentos relativos às condições de produção/recepção (variáveis inferidas) dessas mensagens. (BARDIN, 2016, p. 48).

Quanto à abordagem, esta pesquisa se classifica como qualitativa, de natureza aplicada. Quanto aos objetivos, classifica-se como exploratória e, quanto aos procedimentos, como uma pesquisa ação.

\subsection{As videoaulas e o canal no YouTube}

Os vídeos do canal do projeto foram produzidos de maneira bastante simples, utilizando apenas a webcam do computador para filmagem, um gravador para captura de áudio, o software OBS Studio para captar os movimentos da tela e o software OpenShot para edição dos vídeos. 
Os vídeos disponibilizados no canal foram confeccionados utilizando como roteiro os slides de apresentação em PowerPoint elaborados pelos professores e bolsistas do projeto, para utilização nas aulas presenciais dos cursos ministrados. Desta forma, os vídeos apresentam o mesmo conteúdo das aulas, porém distribuídos em pequenos vídeos pedagógicos. Nesta perspectiva, os slides utilizados nas aulas foram adaptados com relação a tamanho de letra, distribuição do conteúdo no slide e ajuste para aparecer a imagem do bolsista no canto inferior esquerdo do vídeo narrando a explicação, proporcionando assim uma melhor visualização, tanto através do computador quanto através de aparelhos menores como tabletes e smartphones.

Essa produção é uma atividade inovadora dentre as atividades desenvolvidas pelo projeto GAMA. O estilo dos vídeos tenta aliar a precisão matemática a uma linguagem informal, mais próxima do estudante.

A seguir, encontram-se detalhados os conteúdos dos vídeos do curso de matemática básica. Este curso tem suas aulas distribuídas em três semanas, sendo duas aulas em cada sábado nos turnos manhã ou tarde. Ou seja, no primeiro sábado são abordadas as aulas 1 e 2, no segundo, as aulas 3 e 4 e, no terceiro, as aulas 5 e 6 .

Os conteúdos das aulas de matemática básica são distribuídos da seguinte forma:

- Aula 1 - conjuntos numéricos; pertinência e inclusão; regra de sinais; intervalos reais; operações com intervalos; decomposição em fatores primos; mínimo múltiplo comum; operações e propriedades das frações.

- Aula 2 - potências em $\mathbb{R}$; propriedades das potências; potências de base 10; unidades de medida.

- Aula 3 - raízes em $\mathbb{R} ;$ propriedades das raízes; racionalização.

- Aula 4 - fatoração; produtos notáveis.

- Aula 5: - expressões algébricas; valor numérico; simplificação de frações algébricas; multiplicação/divisão de frações algébricas; soma/subtração de frações algébricas.

- Aula 6 - polinômios; operações com polinômios; dispositivo prático de Briot-Ruffini. As videoaulas foram numeradas e disponibilizadas no canal do GAMA ${ }^{1}$ no YouTube, de tal forma que os estudantes possam acessá-las na ordem em que elas são abordadas 
nas aulas presenciais. As videoaulas foram também disponibilizadas na página institucional do projeto GAMA².

Com o objetivo de dimensionar a utilização dos vídeos pelos estudantes, os autores apresentam neste artigo dados acerca da quantidade de inscritos no referido canal e visualizações dos vídeos. A coleta destes dados foi realizada na página do canal em outubro de 2019.

\subsection{Os grupos no WhatsApp}

Com o objetivo de melhor compreender a respeito da importância do grupo do Projeto GAMA no WhatsApp e responder à pergunta norteadora desta pesquisa, realizouse uma análise das mensagens do grupo.

Foram acessadas/analisadas todas as mensagens do grupo, entre os dias 17 de novembro de 2018 (data de criação) e 12 de setembro de 2019. Depois de sucessivas leituras das mensagens, elas foram classificadas em cinco categorias que serão listadas na sequência deste trabalho. No dia 25 de agosto de 2019, o grupo no WhatsApp atingiu o limite máximo de 256 participantes. Por causa dessa limitação surgiu, no mesmo dia, o segundo grupo. Para as mensagens deste segundo grupo, também foi feito o mesmo procedimento. Em todas as cinco categorias foram contabilizadas as mensagens de ambos os grupos, em todos os seus formatos possíveis (texto, áudio, vídeo, imagem, GIFs, etc).

A seguir, são apresentadas as categorias utilizadas para análise dos dados obtidos.

\section{Categoria 1: Divulgação/Informativos}

Nesta categoria estão inclusas as mensagens relacionadas à divulgação dos horários de monitoria do projeto, avisos das novas turmas das Atividades de Reforço em Cálculo bem como a disponibilização do material utilizado, alterações nas salas de aula, mensagens de objetos achados e perdidos, divulgações das Semanas Acadêmicas, horários e trajetos de ônibus, divulgação de editais, componentes curriculares ofertadas, entre outros.

Categoria 2: Dúvidas dos Alunos 
Nesta categoria estão inclusas as mensagens relacionadas às dúvidas dos alunos referentes a conteúdos de matemática em geral, principalmente nos conteúdos de Matemática Básica, Cálculo e Geometria Analítica.

Categoria 3: Respostas de Bolsistas/Professores

Nesta categoria estão inclusas as mensagens relacionadas às respostas referentes às dúvidas citadas na categoria 2. Estas respostas foram fornecidas exclusivamente por bolsistas e professores do projeto.

Categoria 4: Repostas de Alunos

Nesta categoria estão inclusas as mensagens relacionadas às respostas referentes às dúvidas citadas na categoria 2. Estas respostas foram fornecidas exclusivamente por alunos não-bolsistas do Projeto GAMA.

\section{Categoria 5: Outros}

Nesta categoria estão inclusas as mensagens de saudação (como por exemplo: "bom dia"); agradecimentos; vendas de materiais escolares; mensagens de política, religião, futebol; discussões; mensagens apagadas; vídeos, imagens e GIFs não relacionados com ensino-aprendizagem de matemática em geral.

Salienta-se que a categoria 5 procurou englobar todas as mensagens que não se adequavam às demais categorias e que eram, estas sim, o principal foco desta pesquisa que buscava investigar o potencial colaborativo desta ferramenta no processo de ensino/aprendizagem em matemática.

\section{RESULTADOS E DISCUSSÕES}

O canal do projeto já conta com 31 vídeos, disponibilizados de forma aberta e gratuita para todos os interessados. O canal alcançou 124 inscritos e mais de 2.260 visualizações, no período de 2 de março de 2018 quando publicado o primeiro vídeo, até 28 de outubro de 2019.

Essa iniciativa do GAMA ainda continua em andamento, com a elaboração dos vídeos referentes ao conteúdo do curso de Funções e do curso de Funções 
Trigonométricas, Exponenciais e Logarítmicas para posterior gravação, cuja finalização e publicação estão previstas para o segundo semestre de 2019.

Gallo e Pinto (2010) ressaltam três efeitos transformadores das TDICs, ao afirmarem que estas

[...] alteram a estrutura de interesses, mudam o caráter dos símbolos e modificam a natureza da comunidade. Assim, alteram as coisas em que pensamos, mudam as coisas com as quais pensamos e modificam a área em que se desenvolve o pensamento. É uma nova forma em lidar com a aprendizagem, com as relações de poder, com o repertório de signos, a gestão, o acesso e o armazenamento da informação, as distâncias, o tempo e o espaço. (GALLO e PINTO, 2010, p. 8)

Os alunos que frequentam os cursos no modelo de aula presencial, são incentivados a assistirem os vídeos do canal. O formato dos vídeos contempla a apresentação do conteúdo e a imagem do bolsista narrando a explicação. Este formato tem sido avaliado positivamente pelos estudantes. Como já preconizava Moran (2000), no começo do século,

Com o aumento da velocidade e de largura de banda, ver-se e ouvir-se a distância será corriqueiro. O professor poderá dar uma parte das aulas da sua sala e será visto pelos alunos onde eles estiverem. Em uma parte da tela do aluno aparecerá a imagem do professor, ao lado um resumo do que está falando. O aluno poderá fazer perguntas no modo chat ou sendo visto, com autorização do professor, por este e pelos colegas. Essas aulas ficarão gravadas e os alunos poderão acessá-las off-line, quando acharem conveniente. (MORAN, 2000, p.141)

Neste sentido, Moran, Masetto e Behrens (2013, p. 56) destacam que "a linguagem audiovisual desenvolve múltiplas atitudes perspectivas: solicita constantemente a imaginação e reinveste a afetividade com um papel de mediação primordial no mundo, ao passo que a linguagem escrita desenvolve mais o rigor, a organização, a abstração e a análise lógica".

Com a análise realizada nos grupos do Projeto GAMA no WhatsApp, foi constatado que a categoria 1 (Divulgação/Informativos) obteve 32\% do total de mensagens. A categoria 2 (Dúvidas dos Alunos) somou 14\% das mensagens. A categoria 3 (Respostas de 
Bolsistas/Professores) totalizou $12 \%$ do total. A categoria 4 (Repostas de Alunos) alcançou $8 \%$ das mensagens e a categoria 5 (Outros) obteve 34\% das publicações.

Como um dos objetivos do grupo era também proporcionar um espaço integrativo, para estudantes de diversos cursos da UFPel, os administradores do grupo procuravam não "policiar" o conteúdo das mensagens, a menos que elas estivessem totalmente desconectadas do objetivo inicial do grupo. Esta postura, acarretou um percentual significativo na categoria 5.

Constata-se que aproximadamente dois terços das mensagens está distribuída nas categorias "Divulgação/informativos" e "Outros". Entretanto, é expressivo o número total de mensagens referentes às dúvidas e respostas em geral, pois os 34\% (soma das porcentagens das categorias 2,3, e 4) representam 1.249 mensagens. Nesta perspectiva, ferramentas como esta permitem que o tempo destinado a aula se estenda para além do encontro presencial, como destaca Moran (2000)

Hoje entendemos por aula um espaço e tempo determinados. Esse tempo e espaço cada vez serão mais flexíveis. O professor continua "dando aula" quando está disponível para receber e responder mensagens dos alunos, quando cria uma lista de discussão e alimenta continuamente os alunos com textos, páginas da Internet, fora do horário específico da sua aula. Há uma possibilidade cada vez mais acentuada de estarmos todos presentes em muitos tempos e espaços diferentes, quando tanto professores quanto os alunos estão motivados e entendem a aula como pesquisa e intercâmbio, supervisionados, animados, incentivados pelo professor. (MORAN, 2000, p.142)

O crescente acesso aos vídeos produzidos e disponibilizados pelo projeto GAMA agregam-se a uma tendência educacional mundial de incorporação das TDICs ao contexto educacional, como destacam Moran, Masetto e Behrens (2013)

Com o avanço do acesso à banda larga, o streaming de vídeo e áudio se incorpora cada vez mais no cotidiano (...) O celular serve para conversar, enviar mensagens, acessar a internet, tirar e enviar fotos. As tecnologias caminham na direção da integração, da instantaneidade, da comunicação audiovisual e interativa. (MORAN, MASETTO e BEHRENS, 2013, p. 41-42) 
O número expressivo de troca de mensagens nos grupos de WhatsApp do GAMA indica que esta possibilidade de comunicação foi incorporada à prática pedagógica e possivelmente representou um acréscimo na aprendizagem dos participantes.

\section{CONCLUSÕES}

É possível constatar que os vídeos produzidos pelo GAMA se apresentam como uma alternativa bastante promissora, uma vez que a quantidade de acessos aos mesmos no canal do YouTube vem crescendo consideravelmente, na medida em que novos vídeos são produzidos e disponibilizados. Cabe salientar também que os vídeos produzidos apresentam um diferencial em relação a muitos outros encontrados na internet, pois possuem um caráter institucional por estarem atrelados ao nome de uma instituição de ensino superior.

Vale ressaltar que o fato de os vídeos terem como base o material utilizado em sala de aula, nos cursos presenciais do GAMA, os aproxima das atividades desenvolvidas em aula. Com isso, os alunos podem revisar o conteúdo visto em sala de aula mesmo que em dias posteriores à aula, esclarecendo alguma dúvida que tenha restado da mesma ou que até mesmo não tenham se sentido à vontade para perguntar no momento em que determinado conteúdo foi apresentado em sala de aula.

Também cabe salientar que esta atividade proporciona aos bolsistas, alunos de Licenciatura em Matemática, uma experiência com gravação e edição de videoaulas, além do exercício da prática docente.

Em relação à análise dos conteúdos das mensagens dos grupos de WhatsApp, constata-se o potencial desta ferramenta para proporcionar melhores condições de ensino/aprendizagem, de grande importância tanto para os alunos quanto para o projeto como um todo. Fato que pode ser comprovado, por exemplo, pela quantidade significativa de mensagens referentes a dúvidas e respostas dos professores, bolsistas e dos próprios estudantes. 
O fato de alunos, bolsistas e professores estarem presentes no grupo, também se mostra algo positivo nesta iniciativa, pois os próprios alunos podem responder as dúvidas dos seus colegas de universidade (sem a necessidade de intervenção de bolsistas e professores). Isto demonstra o viés colaborativo proporcionado por este recurso. Inclusive no quadro atual de bolsistas, configuram estudantes que participaram ativamente do grupo no WhatsApp enquanto alunos das atividades do GAMA.

Com base nos resultados obtidos, constata-se que o Projeto GAMA além de se apresentar como mais uma oportunidade de aprendizado em matemática, tanto para os bolsistas que nele atuam quanto para os estudantes que o procuram, vem buscando novas formas para que os aprendizes possam usufruir de ambientes mais atrativos e colaborativos.

Finalmente, torna-se imprescindível destacar que projetos de ensino como este necessitam de um investimento financeiro relativamente baixo, em comparação com os valores investidos pela sociedade nas instituições públicas de ensino superior, como é o caso da UFPel. Desta forma, o envolvimento efetivo da comunidade acadêmica (servidores e estudantes bolsistas) neste tipo de atividade certamente representa um ganho, tanto do ponto de vista social quanto financeiro.

\section{REFERÊNCIAS}

BORBA, M. C.; OECHSLER, V. Tecnologias na educação: o uso dos vídeos em sala de aula. Revista Brasileira de Ensino de Ciência e Tecnologia, Curitiba. 2018; v. 11, n.2, p. 391 - 423.

BARDIN, L. Análise de Conteúdo. São Paulo: Edições 70; 2016.

CATAPANI, E. C. Cálculo em Serviço: um estudo exploratório. Bolema, Rio Claro - SP. 2001; v.14, n.16, p. $48-62$.

DÖRR, R. C.; MUNIZ, C. A.; PINA NEVES, R. S. Operações algébricas e funções como obstáculos à aprendizagem no cálculo. In: 1 Simpósio Latino-Americano de Didática da Matemática. 2016; Bonito, MS. Anais do 1 LADIMA, Bonito, MS.

GALLO, P.; PINTO, M. D. G. Professor, esse é o objeto virtual de aprendizagem. Tecnologias na Educação. 2010. p. 1-12. 
GOMES, E. Ensino e aprendizagem de cálculo na engenharia: um mapeamento das publicações nos COBENGEs. In: Encontro Brasileiro de Estudantes de Pós-graduação em Educação Matemática. 2012; Canoas. p. 1-9.

MORAN, J. M. Ensino e aprendizagem inovadores com tecnologias. Informática na Educação: Teoria \& Prática, Porto Alegre. 2000; v. 3, n. 1. p. 137-144.

MORAN, J. M.; MASETTO, M. T.; BEHRENS, M. A. Novas Tecnologias e Mediação Pedagógica. Campinas: Papirus; 2013.

NETO, A. A. O.; VERSUTI, A.; VAZ, W. F. Perspectivas para o uso do WhatsApp no estímulo à aprendizagem dos sujeitos. In: Semana de Licenciatura e Seminário da Pós-graduação em Educação para Ciências e Matemática. 2016; Goiânia. p. 222-236.

REIS, F. S. A tensão entre rigor e intuição no ensino de Cálculo e Análise: A visão de professores-pesquisadores e autores e livros didáticos [tese]. Campinas: Faculdade de Educação, Universidade Estadual de Campinas; 2001. 302 p.

\section{CONTRIBUIÇÕES DE AUTORIA}

\section{1 - Cícero Nachtigall}

Universidade Federal de Pelotas - UFPel, Doutor

https://orcid.org/0000-0003-3869-0062 - ccnachtigall@yahoo.com.br

Contribuição: Conceituação, Curadoria de dados, Metodologia e Supervisão.

\section{2 - Henrique David Campelo}

Universidade Federal de Pelotas - UFPel, Graduando em Licenciatura em Matemática https://orcid.org/0000-0001-6008-5577 - henriquedavidcampelo@hotmail.com Contribuição: Conceituação, Curadoria de Dados, Investigação e Metodologia

\section{3 - Pierre Teixeira da Silva}

Universidade Federal de Pelotas - UFPel, Mestrando em Educação Matemática no Programa de Pós-Graduação em Educação Matemática (PPGEMAT) pela UFPel. https://orcid.org/0000-0001-8930-776X - pierre_pts@hotmail.com Contribuição: Curadoria de Dados, Investigação e Metodologia.

\section{4 - Rejane Pergher}

Universidade Federal de Pelotas - UFPel, Doutora https://orcid.org/0000-0001-6707-9882 - rejane.pergher@gmail.com Contribuição: Escrita - rascunho original e escrita - revisão e edição. 


\section{COMO CITAR ESTE ARTIGO}

NACHTIGALL, C.; et al. O uso de tecnologias digitais no ensino de cálculo na UFPel: Uma análise acerca das iniciativas do projeto GAMA. Ciência e Natura, Santa Maria, v. 43, e33, p. 1-18, 2021. Disponível em: https://doi.org/10.5902/2179460X40950. Acesso em: dia, mês (abreviado), ano. 